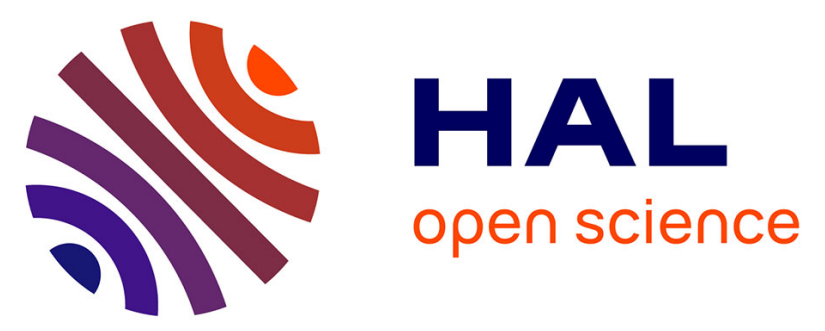

\title{
Predictive dynamic model of the negative lightning discharge based on similarity with long laboratory sparks. Part 1: physical process and modeling
} Abderrahmane Beroual, Jean Hubert Rakotonandrasana, Issouf Fofana

\section{- To cite this version:}

Abderrahmane Beroual, Jean Hubert Rakotonandrasana, Issouf Fofana. Predictive dynamic model of the negative lightning discharge based on similarity with long laboratory sparks. Part 1: physical process and modeling. IEEE Transactions on Dielectrics and Electrical Insulation, 2010, 17 (5), pp.1551 - 1561. 10.1109/TDEI.2010.5595557 . hal-00539057

\section{HAL Id: hal-00539057 https://hal.science/hal-00539057}

Submitted on 25 Mar 2011

HAL is a multi-disciplinary open access archive for the deposit and dissemination of scientific research documents, whether they are published or not. The documents may come from teaching and research institutions in France or abroad, or from public or private research centers.
L'archive ouverte pluridisciplinaire HAL, est destinée au dépôt et à la diffusion de documents scientifiques de niveau recherche, publiés ou non, émanant des établissements d'enseignement et de recherche français ou étrangers, des laboratoires publics ou privés. 


\title{
Predictive Dynamic Model of the Negative Lightning Discharge Based on Similarity with Long Laboratory Sparks - Part 1: Physical Process and Modeling
}

\author{
A. Beroual ${ }^{1}$, J-H. Rakotonandrasana ${ }^{1}$ and I. Fofana ${ }^{2}$ \\ ${ }^{1}$ Ecole Centrale de Lyon, AMPERE Laboratory, CNRS UMR 5005 \\ 36 avenue Guy de Collongue 69134 Ecully, France \\ ${ }^{2}$ Université du Québec à Chicoutimi, ISOLIME, Qc, Canada
}

\begin{abstract}
This paper presents a predictive dynamic model enabling a description of the whole negative lightning discharge. The proposed model takes into account the different phases of the propagation (i.e., the initiation of the first corona, the pilot leader, the negative and space leaders and their junction up to the final jump). This model is based on an $L C R$ line electrical network parameters derived with electromagnetic field, physical laws and gas discharge theories $(L, C$ and $R$, being respectively the inductance, the capacitance and the resistance). Criteria for initiation, development, stand-off and some atmospheric conditions are also introduced. From this model the main macroscopic parameters of the negative lightning can be computed.
\end{abstract}

Index Terms - Negative lightning discharge, modeling, propagation.

\section{LIST OF SYMBOLS}

$\alpha$

$b$

$\beta_{n, l}$

$\beta_{\mathrm{p}, \mathrm{sp}, 1}$

$\beta_{\mathrm{n}, \mathrm{sp}, 1}$

$c$

$c_{0}$

$C_{0}$

$C_{j}$

$C_{s, j}$

$\mathrm{D}_{\mathrm{f}}$

$d L_{n, l}$

$d L_{n, l, z}$

D

dispersion parameter

absolute temperature, $\mathrm{K}$

barometric pressure, $\mathrm{mmHg}$

barometric pressure, $\mathrm{kPa}$ the head of streamers, $F$ magnetic field decays to zero, $m$

leader step's axial length, $m$

cloud-earth distance, $\mathrm{m}$ fraction of the available energy used for the displacement of the negative electrode leader

fraction of the available energy used for the displacement of the positive spatial leader

fraction of the available energy used for the displacement of the negative spatial leader

standard atmospheric pressure, $1.013 \mathrm{kPa}$

cloud-earth system geometric capacitance, $\mathrm{F}$

Capacitance between streamers head and earth, $\mathrm{F}$

capacitance between the discharge channel tip and

distance from the leader channel where the radiated

length of the leader propagation during a step $\mathrm{dt}, \mathrm{m}$ $d t$

$\Delta t$

$\delta$

e

$E_{A}$

$\mathrm{E}_{\mathrm{r}}$

$E_{s t}$

$E_{s}$

$E_{0}$

$E_{C}$

$E_{l, p}$

$E(z)$

$\mathrm{E}_{\mathrm{n}, 1}$

$\mathrm{E}_{\mathrm{p}, \mathrm{sp}, 1}$

$\mathrm{E}_{\mathrm{n}, \mathrm{sp}, 1}$

$\mathrm{E}_{\mathrm{n}, \mathrm{S}}$,

$\mathrm{E}_{\mathrm{p}, \mathrm{sp}, \mathrm{S}}$,

$\mathrm{E}_{\mathrm{n}, \mathrm{sp}, \mathrm{S}}$

$E_{m s}$ computational step, $\mathrm{s}$

duration of the final jump phase, $\mathrm{s}$

relative air density factor

electron charge, $1.610^{-19} \mathrm{C}$

mean field in the unbridged gap, $\mathrm{MV} / \mathrm{m}$

reduced electric field

streamer stability field, $\mathrm{kV} / \mathrm{cm}$

electric field within the streamer zone, $\mathrm{MV} / \mathrm{m}$

breakdown field strength at atmospheric pressure and sea level, MV/m

the breakdown field of air, $\mathrm{MV} / \mathrm{m}$

field at the negative electrode leader tip, $\mathrm{MV} / \mathrm{m}$

air electric field strength at altitude $\mathrm{z}, \mathrm{MV} / \mathrm{m}$

mean fields within the streamers zone of negative electrode leader, $\mathrm{MV} / \mathrm{m}$

mean fields within the positive spatial leader, $\mathrm{MV} / \mathrm{m}$ mean fields within the negative spatial leader, $\mathrm{MV} / \mathrm{m}$ mean fields within the streamers zone of negative electrode leader, $\mathrm{MV} / \mathrm{m}$

mean fields within the streamers zone of positive spatial leader, MV/m

mean fields within the streamers zone of negative spatial leader, MV/m

mean field along the streamers, $\mathrm{MV} / \mathrm{m}$ 
$\mathrm{E}_{\mathrm{Z}} \quad$ mean field within the uncrossed electrode gap (i.e., between the head of the entire discharge channel and the ground), $\mathrm{MV} / \mathrm{m}$

$E_{Z, I-p}$ mean field within the gap between the streamers zones of both negative electrode leader and positive spatial leaders, $\mathrm{MV} / \mathrm{m}$

$\xi \quad$ number ranging from 0 to 1 generated randomly

$\varphi \quad$ instantaneous random angle between the leader trajectory and the vertical axis, rd

$\gamma \quad$ ratio between the specific heat at constant volume and constant pressure

$H \quad$ cloud diameter, $\mathrm{m}$

I total discharge current, A

$I_{s} \quad$ current flowing in the streamer zone, $\mathrm{A}$

$k$ the Boltzmann constant, $1.3810^{-23} \mathrm{~J} \mathrm{~K}^{-1}$

$L_{j} \quad$ Leader channel branch inductance, $\mathrm{H}$

$\mathrm{L}_{n, 1} \quad$ length of the negative electrode leader, $\mathrm{m}$

$\mathrm{L}_{\mathrm{p}, \mathrm{sp}, \mathrm{l}} \quad$ length of the positive spatial leader, $\mathrm{m}$

$\mathrm{L}_{\mathrm{n}, \mathrm{sp}, \mathrm{l}} \quad$ length of the negative spatial leader, $\mathrm{m}$

$\mathrm{L}_{\mathrm{lu}} \quad$ leader's inductance per unit length, $\mathrm{H} / \mathrm{m}$

$L_{n, l, z} \quad$ axial length of the main negative leader, $\mathrm{m}$

$L_{f j} \quad$ critical final jump length, $m$

$\mathrm{L}_{\mathrm{t}, \mathrm{z}} \quad$ total axial length of the negative discharge, $\mathrm{m}$

$\lambda_{s} \quad$ per unit length resistance of the corona leader, $\Omega / \mathrm{m}$

$\lambda_{l} \quad$ per unit length resistance of the leader, $\Omega / \mathrm{m}$

$N \quad$ gas density of the negative electrode leader

$\mathrm{N}_{0} \quad$ gas number density at the time $t_{0}$ at which the leader section is formed, $\mathrm{m}^{-3}$

$P_{j} \quad$ power injected in the gap, $\mathrm{W}$

$Q \quad$ charge injected into the gap, C

$R_{0} \quad$ equivalent ground impedance, $\Omega$

$r_{l 0} \quad$ initial radius of the leader channel, $\mathrm{m}$

$r_{l} \quad$ negative leader tip radius, $\mathrm{m}$

$r_{e} \quad$ radius of the hyperboloidal electrode equivalent to the leader tip, $m$

$\mathrm{r}_{1} \quad$ curvature radius of the equipotential surface at the considered point, $\mathrm{m}$

$R_{f j} \quad$ leader resistance $R_{j}$ just before the beginning of the final jump, $\Omega$

$R_{j} \quad$ Leader channel branch resistance, $\Omega$

$\rho \quad$ air density, $\mathrm{kg} \cdot \mathrm{m}^{-3}$

$S \quad$ streamer length, $\mathrm{m}$

$\mathrm{S}_{\mathrm{n}, \mathrm{S}} \quad$ length of the streamers zone of negative electrode leader, $\mathrm{m}$

$\mathrm{S}_{\mathrm{p}, \mathrm{sp}, \mathrm{l}}$

$\mathrm{S}_{\mathrm{n}, \mathrm{sp}, \mathrm{I}}$

$S_{n, S, Z}$

$\sigma$

$t_{0}$

$\tau_{0}$

$U_{c}$
$\mathrm{U}_{\mathrm{i}}$ inception voltage at the head of negative discharge (i.e., at the head of the whole negative discharge channel), MV

$V_{j} \quad$ voltage at the electrode leader tip, MV

$V_{0} \quad$ voltage drop along $\mathrm{C}_{0}, \mathrm{MV}$

$\mathrm{V}_{\mathrm{j}} \quad$ voltage across the $\mathrm{C}_{\mathrm{j}}$, MV

$v_{j, n, l} \quad$ leader propagation velocity from the negative charge reservoir, $\mathrm{m} / \mathrm{s}$

$\mathrm{v}_{\mathrm{j}, \mathrm{p}, \mathrm{sp}, \mathrm{l}} \quad$ velocity of the positive spatial leader, $\mathrm{m} / \mathrm{s}$

$\mathrm{v}_{\mathrm{j}, \mathrm{n}, \mathrm{sp}, 1} \quad$ velocity of the negative spatial leader, $\mathrm{m} / \mathrm{s}$

$\mu_{e} \quad$ electron mobility, $0.18 \mathrm{~m}^{2} \mathrm{~V}^{-1} \mathrm{~s}^{-1}$

$\Gamma_{\mathrm{s}, \mathrm{j}} \quad$ solid angle between the discharge channel tip and the head of streamers, sr

$\Gamma_{\mathrm{j}} \quad$ solid angle associated to capacitance $\mathrm{C}_{\mathrm{j}}$, sr

$W_{j} \quad$ energy injected in the gap, $\mathrm{J}$

$z \quad$ the altitude, $\mathrm{km}$

$Z \quad$ gap uncrossed by the discharge, $\mathrm{m}$

$Z_{1-p} \quad$ axial length between the streamers zones (negative electrode leader and negative spatial leaders), $\mathrm{m}$

\section{INTRODUCTION}

A large number of papers and books on the lightning phenomenon, on both positive and negative have been published with the aim of improving our basic knowledge on the process involved and consequently to propose mitigation methods against the devastating effects on engineering systems (direct strikes and nearby electromagnetic fields radiated by the leaders and return stroke) [1-5].

Reviews of the present state of our knowledge on the negative atmospheric discharge can be found in the literature $[1,2]$. One may distinguish various types of lightning discharges including discharges within a cloud, discharges between clouds and cloud-earth discharges. In this paper, only the last type is considered.

In situ lightning investigation is a cumbersome task due to its random aspects. Even though it is presently possible to trigger lightning discharge artificially, the physics involved in this phenomenon is not yet fully understood and many questions remain unanswered. Moreover, artificial triggering of lightning is difficult to perform.

The study of the negative lightning is very important since most cloud-earth lightning discharge (about 90\%) in temperate regions of the world is negative. Negative lightning discharges have been the subject of very intensive experimental investigations $[1,2,5,6]$. Contrary to the positive lightning for which many theoretical models are available [3 - 6], research to derive models for the negative lightning is still at its earlier stages. This is due to the complexity of the mechanisms involved in the propagation processes. The development of a negative lightning discharge model allowing predicting the main macroscopic parameters will be very useful for the design and protection of engineering structures against direct and indirect strikes. 
This contribution presents some development based on our previous work related to positive discharge in long air gaps with application to positive lightning [3]. A dynamic mathematic model enabling a description of the evolution of the complete negative lightning discharge, taking into account the different phases of the propagation (i.e., the initiation of the first corona, the negative and space leaders and the junction of leaders) is presented. The proposed model is based on the idea that a substantial similarity exists between lightning phenomena and discharge in long air gaps $[1,2]$. This model is based on a LCR dynamic equivalent electrical network (L, $\mathrm{C}$ and $\mathrm{R}$ being respectively the inductance, the capacitance and the resistance). These parameters vary with time according to the discharge characteristics and geometry.

\section{FUNDAMENTAL PROCESSES IN NEGATIVE LIGHTNING DISCHARGES}

It is well known that most lightning flashes occur within a cloud or between clouds. The discharge initiation within a cloud is not well fully understood. It seems that the discharges are initiated in the vicinity of the pocket of negative charges where the electric field is enhanced. However, measurements recorded using sounding techniques indicate that this field does not exceed 150 to $200 \mathrm{kV} / \mathrm{m} \mathrm{[7]}$. Such values are 5 to 10 times lower than the breakdown field of air $\left(\mathrm{E}_{\mathrm{C}}\right)$ and hence insufficient to ionize air and start the development of a discharge. The electric field is however enhanced at the poles (extremities) of hydrometeors and more particularly of large water drops, possibly reaching values higher than $E_{C}$, and able to initiate coronas [8]. Therefore, the initiation of atmospheric discharges seems to be closely related to the presence of drops of large size. These coronas consisting of a series of avalanches develop into a plasma channel of several $\mathrm{km}$.

In a macroscopic point of view, there are two available theories allowing explaining such a development. The first one, developed by Schonland [9], proposes the unidirectional propagation of the discharge (leader). The leader is initiated from a pocket of charge (space charge) where the field is enhanced, and progresses toward a zone of opposite polarity. The propagation is similar to that produced in laboratory discharge between a HV electrode and a grounded plate. The charge pocket is similar to the electrode and provides the required energy to feed the leader propagation.

The second theory was developed by Kasemir [10] who first imagined the existence of bi-leader process. Contrary to the first theory, this one requires the presence of two bidirectional discharges, developing from a unique point; the discharge propagating in the field direction is referred as positive while that one propagating in the opposite is negative. This last hypothesis seems to be confirmed by the interferometric localisation of VHF sources emitted by discharges [11-13]. The measurements achieved by Richard et al [11], Mazur [12] and Bondiou et al [13] evidenced the bi-directional development of natural flashes.

From fast camera recordings working in streak mode, it has been shown that the negative lightning discharge propagates by steps characterized by strong reilluminations $[1,2,14,15,16]$. These recordings also emphasized that the mechanisms involved in the development of such a discharge are very complex. Moreover, it is well established that the propagation sequences of this discharge (Figure 1) may be schematically described by the following main phases [17]: (1) the inception and development of a first corona or corona-streamers; (2) after the extinction of the first corona, there is a short dark period followed by the inception and development of a bipolar system called "pilot". This latter consists of two coronas of opposite polarity: the positive corona develops toward the cloud while the negative corona propagates toward the ground; (3) the development of a space leader from a 'space stem', actually a previous pilot inception point. The space leader propagation, as a simultaneous bidirectional discharge toward the cloud and the ground is followed by the inception of negative leader from the cloud ; and finally (4) the junction between both space leader and negative electrode leader producing a sudden elongation of the channel. This junction is accompanied by a strong reillumination of the discharge channel while a new corona takes place at the head of the discharge channel: this completes the stepwise propagation mechanism. The entire phenomenon resumes and will be repeated until the ground is reached.

\section{THEORETICAL BACKGROUND}

\subsection{FIRST CORONA INITIATION}

The initiation of first corona can be determined using either Raether criterion [18] or Peek formula [19]. Both criteria determine the conditions required to initiate an electronic avalanche of sufficient size enabling the development of a corona. This first corona consists of luminous filaments of a ramified structure - the streamers.

\subsection{CRITERION FOR THE MAIN NEGATIVE LEADER GROWTH}

The growth of the negative electrode leader tip is mainly governed by the field $E_{l, p}$ at its tip. This field can be calculated by assuming the negative leader tip to an equivalent electrode [20]. $E_{l, p}$ may be therefore estimated using a hyperboloidal approximation [20] :

$$
E_{l, p}=\frac{2 V_{j}}{r_{e} \ln 4\left(\frac{D-L_{n, l, z}}{r_{e}}\right)}
$$

$V_{j}$ is the voltage at the electrode leader tip. $r_{e}$ is the equivalent curvature radius of the leader tip assumed to be a hyperboloid electrode; it can be computed using the empirical relationship proposed in the literature [20]. 


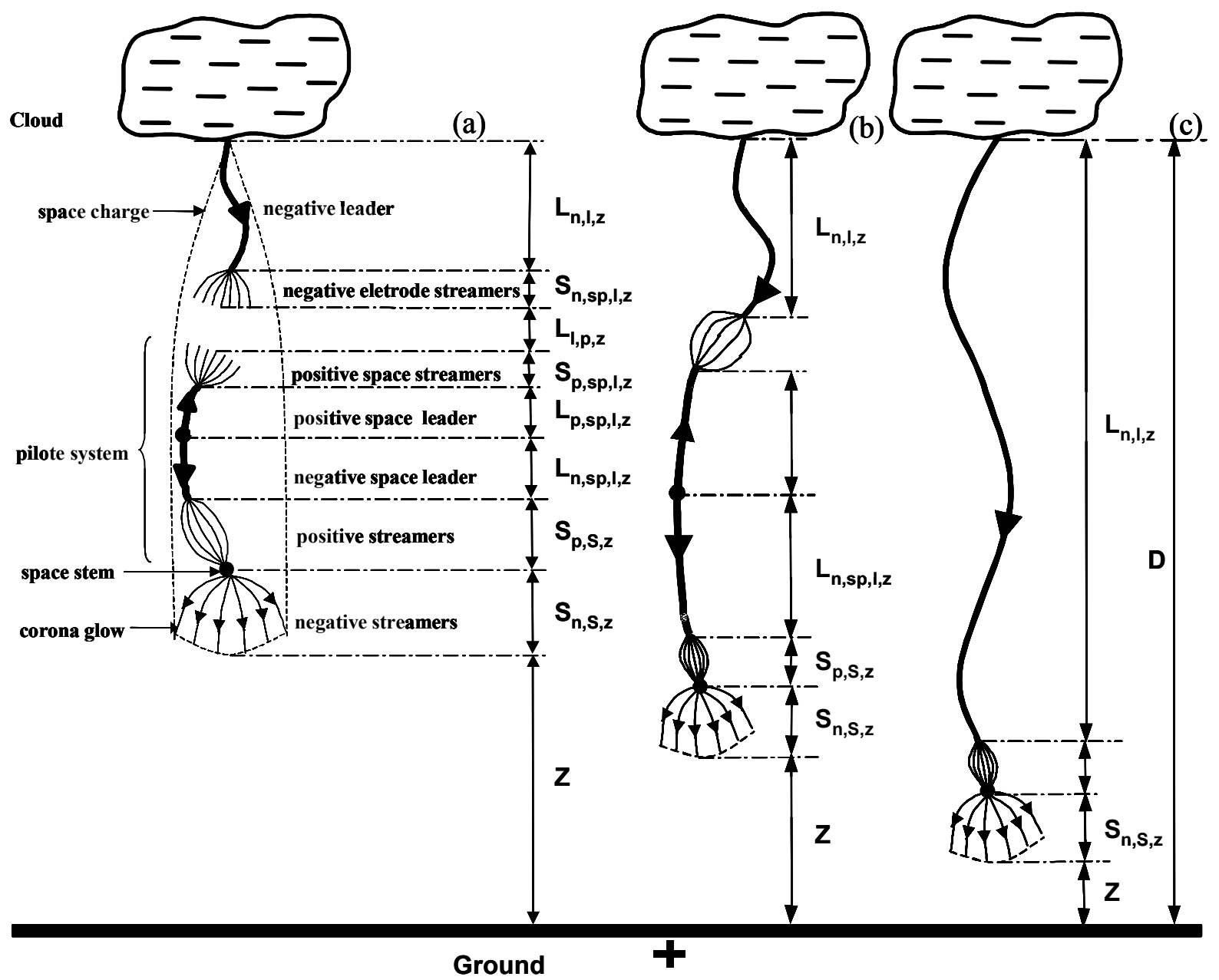

Figure 1. Lightning schematic process

$D$ is the cloud - earth distance. $L_{n, l, z}$ is the axial length of the main negative leader.

Note that the electric field may be computed from numerical techniques. However, the following analytical relationships which help reducing computation time were used.

Depending on the value of $E_{1, p}$, the leader channel will propagate or not. If $\mathrm{E}_{\mathrm{l}, \mathrm{p}}$ is higher than the critical field $E_{c}$ to keep the corona effect alive, the leader channel will propagate through the gap. Otherwise, the leader channel will progressively cool and finally disappears, unless the applied voltage characteristics are able to re-activate it. $\mathrm{E}_{\mathrm{c}}$ may be calculated using Peek's formula [21]

$$
E_{c}=E_{0}\left(1+\frac{0.308}{\left(r_{e} \delta\right)^{1 / 2}}\right)
$$

where $\mathrm{E}_{0}=3 \mathrm{MV} / \mathrm{m}$ represents the breakdown field strength at atmospheric pressure and sea level $[23,24]$ and $\delta$, the relative air density [22].

$\delta=\frac{0.392 b}{\alpha}=\frac{2.92 c}{\alpha}$ where $\mathrm{b}$ is the barometric pressure in $\mathrm{mmHg}$ (or $\mathrm{c}$ the barometric pressure in $\mathrm{kPa}$ ) and $\alpha$ is the absolute temperature (in Kelvin).

The electric field strength for air breakdown that is used in the application of the leader inception criterion is corrected for variations in altitude $\mathrm{z}$ (in $\mathrm{km}$ ) and air pressure $\mathrm{c}$ (in $\mathrm{kPa}$ ).

The application of such a correction is particularly important when considering lightning protection systems installed at high altitudes [23]. This variation is modeled using a simplified linear approximation [23, 24]

$\mathrm{E}(\mathrm{z})=\mathrm{E}_{0}(1-0.09 \mathrm{z})$

Changes of pressure with altitude are made to good approximation using

$$
c(z)=c_{0} \exp (-z / 8)
$$

where $c_{0}$ is the standard atmospheric pressure of $1.013 \mathrm{kPa}$ and $z$ is the altitude $(\mathrm{km})[23,24]$. Humidity corrections change $\mathrm{E}_{\mathrm{O}}$ by up to $5 \%$ and hence can be ignored [23]. In any case, humidity variations are governed almost entirely by the prevailing weather conditions during the thunderstorm. 
It has been shown that the stability field is equivalent to the average field along the streamer extension [25]; therefore, if the average field is fixed, the length of the negative corona $\mathrm{S}_{\mathrm{n}, \mathrm{S}, \mathrm{Z}}$ is directly given by the graphical construction (Figure 2), i.e. geometrical method by considering the electric field within the corona region as constant [25]. $\mathrm{S}_{\mathrm{n}, \mathrm{S}, \mathrm{Z}}$ is determined using the electrostatic potential distribution before and after corona development.

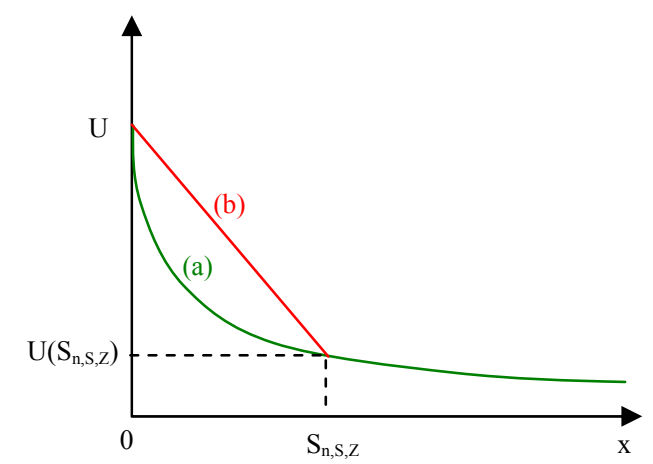

Figure 2. Potential distribution in the gap before (a) and after (b) the development of the negative corona streamers: (a) and the straight line voltage of slope $E_{s}$ from the initial potential $U_{i}(\mathrm{~b})$.

\subsection{DEVELOPMENT OF THE PILOT SYSTEM}

Both positive and negative coronas are initiated once the criterion related to the electric field at the head of streamers is satisfied [17]. The electric field at the head of coronastreamers (as sketched in Figure 1) is calculated in the same way as for the initiation of the first corona:

$$
E_{s, \text { head }}=\frac{2 V_{s, j}}{r_{s} \ln \left(\frac{4 Z}{r_{s}}\right)}
$$

$Z$ is the gap uncrossed by the discharge; $V_{s, j}$ is the voltage at the streamers head; $r_{s}$ is the negative streamers radius estimated analytically from the stability field [26]. After the extinction of these newly formed coronas, another relaxation process takes place along the pilot system and so on.

\subsection{DEVELOPMENT OF ELECTRODE AND SPACE LEADERS}

The propagation of discharge tip and space leaders are governed by the power $\mathrm{P}_{\mathrm{j}}$ (or energy $\mathrm{W}_{\mathrm{j}}$ ) coming from the cloud and provided to the corona and the pilot system. This power is computed from the equivalent LCR electric circuit, to be described in section 4 . On the other hand, since the negative discharge propagates by steps, the leader propagation is represented by a succession of segments having a length $\mathrm{dL}_{\mathrm{n}, 1}$ (where $\mathrm{dL}_{\mathrm{n}, 1}=\mathrm{vdt}, \mathrm{v}$ and $\mathrm{dt}$ being respectively the leader propagation velocity and the computation time step) making a random angle $\varphi$ with the gap axis, that is $\mathrm{dL}_{\mathrm{n}, \mathrm{l}, \mathrm{z}}=\mathrm{dL}_{\mathrm{n}, \mathrm{l}} \cos \varphi$, $\mathrm{dL}_{\mathrm{n}, \mathrm{l}, \mathrm{z}}$ being the leader step's axial length. Thus the leader propagation velocity from the negative charge reservoir can be calculated using the following relationship [27, 28, 29]

$v_{j, n, l}(t)=\left(\frac{2 \beta_{n, l}}{\rho \pi r_{l}^{2}} \frac{d W_{j}}{d t}\right)^{1 / 3}$ or

$$
v_{j, n, l}(t)=\left(\frac{2 \beta_{n, l}}{\rho \pi r_{l}^{2}} P_{j}\right)^{1 / 3}
$$

where $\rho$ is the air density ( $\rho$ is set to $0.15 \mathrm{~kg} \mathrm{~m}^{-3}$ [30] at $\left.1000^{\circ} \mathrm{K}[15,31]\right)$ and $r_{1}$ is the negative leader tip radius at the time $t_{0}$ at which it is formed [32]. $\beta_{n, 1}$ is the fraction of the available energy used for the displacement of the negative electrode leader $\left(0<\beta_{\mathrm{n}, 1} \leq 1\right)$. Its value was estimated at about $0.1[32,33]$. It appears from these relationships (equation (7) or (8)) that the velocity depends on the energy (power) injected in the gap. Also, for a given voltage, the velocity is proportional to the cube root of the current $\left(\mathrm{v}_{\mathrm{j}, \mathrm{n}, 1} \sim \mathrm{i}_{\mathrm{L}}{ }^{1 / 3}\right)$. Such a relationship has been reported by Bazelyan and Raizer for the positive discharges $[2,34]$. As concerns the numerical values of velocities, considering for instance an applied voltage of 50 $\mathrm{MV}$, a peak current of $10 \mathrm{kA}$ and a value of the leader channel radius of $10 \mathrm{~mm}$, an instantaneous velocity of $1.310^{5} \mathrm{~m} / \mathrm{s}$ is obtained which is a value close to those estimated experimentally.

In the same way, the velocities of both positive and negative spatial leaders $\left(\mathrm{v}_{\mathrm{j}, \mathrm{p}, \mathrm{sp}, \mathrm{l}}\right.$ and $\mathrm{v}_{\mathrm{j}, \mathrm{n}, \mathrm{sp}, \mathrm{l}}$ respectively $)$ can be computed by replacing $\beta_{\mathrm{n}, 1}$ by $\beta_{\mathrm{p}, \mathrm{sp}, 1}$ and $\beta_{\mathrm{n}, \mathrm{sp}, 1}$ respectively. The values of $\beta_{\mathrm{p}, \mathrm{sp}, \mathrm{l}}$ and $\beta_{\mathrm{n}, \mathrm{sp}, \mathrm{l}}$ are much smaller than $\beta_{\mathrm{n}, \mathrm{l}}$. In our modelling, the lengths of spatial leaders are supposed to represent a few percent of that of negative electrode leader.

Using the above relationship, the position of the leader's tip at each step time may be determined. Streamers are taken into account by suitable modifications of the equivalent circuit parameters essentially based on our previous modelling of positive discharge in long air gaps [35].

Thus, the stepwise leader propagation is guaranteed by estimation of the electric field at the leader tip on one hand, and by the junction of leaders during re-illumination on the other hand.

\subsection{VOLTAGE DISTRIBUTION}

Before the junction, the potential drop across the gap is [33]

$$
\begin{aligned}
& U_{c}(t)=\left(E_{n, l} L_{n, l}+E_{n, S} S_{n, S}\right)+\left(E_{p, s p, l} L_{p, s p, l}+E_{p, s p, S} S_{p, s p, l}\right) \\
& +\left(E_{n, s p, l} L_{n, s p, l}+E_{n, s p, S} S_{n, s p, l}\right)+\left(E_{Z, l-p} Z_{l-p}\right)+\left(E_{Z} Z\right)
\end{aligned}
$$

where $E_{n, 1}, E_{p, s p, l}$, and $E_{n, s p, l}$ are the mean fields within the negative electrode leader, the positive spatial leader and the negative spatial leader respectively (Figure 1);

$E_{n, S}, E_{p, s p, S}$, and $E_{n, s p, s}$ are the mean fields within the streamers zone of negative electrode leader, the streamers zone of positive spatial leader and the streamers zone of negative spatial leader respectively (Figure 1);

$\mathrm{L}_{\mathrm{n}, \mathrm{l}}, \mathrm{L}_{\mathrm{p}, \mathrm{sp}, \mathrm{l}}$, and $\mathrm{L}_{\mathrm{n}, \mathrm{sp}, \mathrm{l}}$ are the lengths of the negative electrode leader, the positive spatial leader and the negative spatial leader respectively (Figure 1);

$\mathrm{S}_{\mathrm{n}, \mathrm{S}}, \mathrm{S}_{\mathrm{p}, \mathrm{sp}, \mathrm{l}}$, and $\mathrm{S}_{\mathrm{n}, \mathrm{sp}, \mathrm{l}}$ are the lengths of the streamers zone of negative electrode leader, the streamers zone of positive and negative spatial leaders respectively (Figure 1); 
$E_{Z,-1-p}$ and $E_{Z}$ are the mean fields within the gap between the streamers zones of both negative electrode leader and positive spatial leaders, and the uncrossed electrode gap (i.e., between the head of the entire discharge channel and the ground, see Figure 1);

$Z_{\mathrm{l}-\mathrm{p}}$ and $Z$ are the axial lengths between the streamers zones of both negative electrode leader and negative spatial leaders, and the uncrossed electrode gap (Figure 1). $\mathrm{E}_{\mathrm{n}, 1}$ can be calculated using non-LTE assumptions [30].

Experimental observations $[19,36]$ revealed that the streamers at the head of both negative electrode and positive spatial leaders, which radiate in the ultraviolet light, are not visible likely due to their high resistivity (less ionised zones). In our modelling, these streamers zones are assumed to be parts of the associated leaders and their length, assumed to a few percents of the considered leader channels.

After the junction, the electric field $E_{z}$ of the uncrossed gap can be computed to

$E_{Z}=\frac{U_{c}(t)-U_{i}}{Z}$

$\mathrm{U}_{\mathrm{i}}$ is the inception voltage at the head of negative discharge (i.e., at the head of the whole negative discharge channel).

The length of the leader corona streamers can be deduced from equations (9) and (10).

The use of this formula is justified by the fact that after the junction of negative electrode leader and space leaders, only one leader is formed. Thus, this situation can be considered similar to that of the positive polarity.

\subsection{JUNCTION PROCESS}

The propagation of the positive leader's head towards the cathode leads to the junction with the negative leader propagating in the opposite direction. The two discharges undergo a junction process leading to a strong re-illumination of the whole channel associated with a large current pulse, and resulting in the formation of a longer negative leader. The negative discharge advancement will involve the formation of further pilot system starting near the boundary of the streamer front.

The potential distribution at the end of the re-illumination is calculated from a geometrical method while neglecting the electric field along the channel of newly formed leader. The current injected is sufficient enough to allow the thermalization of the channel leading to a significant drop in the internal field [37]. The leader channel becomes therefore more conductive.

At the tip of the newly-formed leader, a negative corona will be initiated. The length of this corona is also determined by geometrical method [25] (Figure 2).

\subsection{ERRATIC PROPAGATION OF THE DISCHARGE}

The erratic propagation of the discharge is taken into account by introducing the probabilistic law established for positive long air gap discharge by Hutzler and Hutzler [20]. The complete calculation leads to the determination of $\varphi(\varphi$ is a random angle between the segment of the discharge trajectory and the electrode axis). This aspect is taken into account with a probabilistic law characterised by a dispersion parameter "a"

$P(\varphi)=\frac{\sin \varphi}{a} \exp \left(-\frac{1-\cos \varphi}{a}\right)$

with

$a=0.6\left(1+10 r_{l}\right)^{-1}\left(0.8+10^{-10} \frac{d U_{c}(t)}{d t}\right)^{-1}(\mathrm{~m}, \mathrm{~V}, \mathrm{~s})$

where $r_{1}$ is the curvature radius of the equipotential surface at the considered point and $\frac{d U_{c}(t)}{d t}$ (in $V / s$ ) is the time-variation rate of the applied voltage at the considered instant. This empirical formula expresses the fact that the randomness of the leader becomes more marked as the field is less uniform and the voltage increases less rapidly. As a three dimensional computation is considered, $\varphi$ is taken equal to $2 \pi \xi$; where $\xi$ is a number ranging from 0 to 1 generated randomly [38].

In the case, the probability of having $\varphi>\pi / 2$ is not null, the leader may move towards the high voltage electrode. Recall that equation (10) provides a non-null probability of having $|\varphi|>\pi$, which has no physical meaning. For this reason, $\varphi$ has been confined within the range $-\pi<\varphi<\pi$ and equation (11) modified consequently

$$
P(\varphi)=\frac{|\sin \varphi|}{2 a\left(1-\exp \left(\frac{-2}{a}\right)\right)} \exp \left(\frac{\cos \varphi-1}{a}\right)
$$

\subsection{THE FINAL JUMP}

According to Les Renardières Group [36], three different types of final jump may occur. Only the type A is considered in this contribution. For this type, the final jump starts when the negative streamers reach the ground. The arrival of the negative streamers may occur either suddenly (after an elongation of the channel), or during the propagation of the leader and the associated space stem. Thus, the final jump appears to be strongly linked, through its initial conditions, to the propagation mode of the discharge and consequently to the voltage and atmospheric conditions. The height of the final jump is determined by the distance between the negative leader's tip and the ground. This may happen when the negative streamers approach the ground. In almost every case, a positive leader will grow up from the ground. In most case, the elongation of the positive leader is lower or equal to the half height of the final jump. Finally, the development of the final jump is directly linked to the mode of leader propagation. Thus, its spatial and temporal characteristics are distance, voltage characteristic dependent.

The transition from the free development phase to the final jump phase is triggered when the value of the total axial length of the negative discharge $\mathrm{L}_{t, \mathrm{z}}$ (after the junction phase) exceeds the height of the final jump $\mathrm{L}_{\mathrm{fj}}$ which depends only on the voltage at the leader tip [39]. To compute $\mathrm{L}_{\mathrm{fj}}$, an empirical relationship between the breakdown voltage and the height of the final jump is used [39]

$L_{f j}=D-\frac{U_{c}(t)-0.75}{0.44}$

with $D$ in metres and $U_{c}(t)$ in Megavolts. 
Since the final jump, type A, under the negative polarity is similar to that happening under the positive polarity, equation (14) was used.

The triggering of this phase leads inevitably to the breakdown of the gap unless the applied voltage drops substantially. To complete the model, a case of hold off [19] in which the conditions required to bridge the gap are not satisfied, is taken into account. If the mean streamer field

$E_{m s}=\frac{U_{c}(t)-0.75}{D-L_{t, z}}$

( $D$ and $\mathrm{L}_{\mathrm{t}, \mathrm{z}}$ in metres and $\mathrm{U}_{\mathrm{c}}(\mathrm{t})$ in MV) is sufficient, that is higher than $E_{S}$, the leader channel can propagate at a much higher velocity of the order of a few $\mathrm{m} . \mu \mathrm{s}^{-1}[40]$.

\section{GENERAL DESCRIPTION OF THE MODELING}

The extension of our recent model on long air gaps discharge under negative polarity [33] to the negative lightning requires taking into account some specific parameters related to lightning. The general idea consists in representing the negative lightning discharge by an LCR equivalent electrical network similar to that of long negative sparks in laboratory (Figure 3). $n$ is the number of negative leader steps (i.e., the whole discharge channel steps including the attachment process). $\mathrm{R}_{0}$ represents the equivalent ground impedance. Since the value of this impedance does not dependent neither on the voltage polarity nor the cloud - earth distance, it is assumed as a perfect conductor (i.e., a pure resistance); $\mathrm{R}_{0}$ is set to $100 \Omega$ $[27,32]$. Various simulations have shown that changing this value do not affect the results. $\mathrm{C}_{0}$ represents the equivalent cloud - earth capacitance. The electrodes of this condenser are assumed to two conducting discs of diameter $\mathrm{H}$, separated by a distance $D[21,37]$. $\mathrm{H}$ is taken equal to 1000 $\mathrm{m}$. The capacitance $\mathrm{C}_{0}$ is given by

$C_{0}=\frac{\varepsilon_{0} \pi H^{2}}{4 D}$

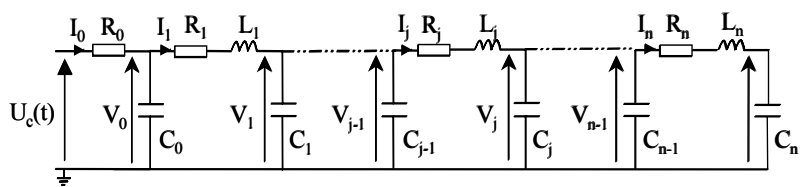

Figure 3. Electrical circuit model describing the whole negative discharges propagation

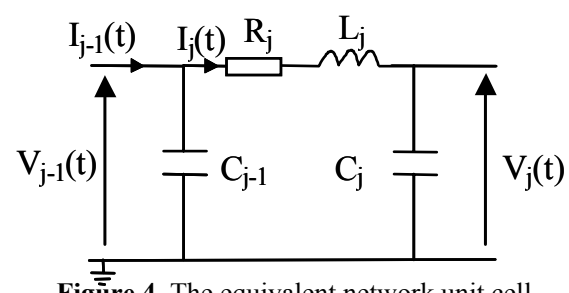

Figüre 4. The equivalent network unit cell

The equations associated with a unit cell $L_{j} C_{j} R_{j}$ (Figure 4), corresponding to a partial displacement, are derived

$L_{j} \frac{d I_{j}}{d t}=V_{j-1}(t)-V_{j}(t)-R_{j} I_{j}(t)$ and

$I_{j-1}(t)-I_{j}(t)=C_{j-1} \frac{d V_{j-1}(t)}{d t}$

From equations (17) and (18), the voltages and currents are deduced. Also the leader current may be computed

$I_{0}(t)=\frac{U_{c}(t)-V_{0}(t)}{R_{0}}$

$V_{0}(t)$ and $U_{c}(t)$ being respectively the $C_{0}$ capacitance voltage and the voltage applied to the gap.

One can also compute the charge injected into the gap; as the sum of the elementary charges, namely

$Q(t)=\sum_{1}^{n} q_{j}=\sum_{0}^{n} \sum_{0}^{t} C_{j} V_{j}(t)$

$\mathrm{V}_{\mathrm{j}}(\mathrm{t})$ being the voltage across the $\mathrm{C}_{\mathrm{j}}$ capacitance and $\mathrm{n}$ the number of the leader steps. It appears from the preceding equations that calculation of the spatio-temporal evolution of the parameters of the discharge (current, charge ...) requires the knowledge of $L_{j}, C_{j}$ and $R_{j}$. The pilot system is also represented by a LCR equivalent network. These elements are calculated in the same manner as for the leader channel. Using digital sampling of the instantaneous voltage $V_{j}$ and current $i_{j}$, the power $P_{j}$ and the corresponding energy $W_{j}$ injected into the electrode gap are computed

$P_{j}=V_{j} I_{j}$

$W_{j}=\sum_{0}^{t} V_{j} I_{j} d t$

Knowing the values of the power (or energy) injected into the gap, the instantaneous velocity is also computed using equation (7) or (8).

The elements of the equivalent electrical circuit, $R_{j}, L_{j}$ and $\mathrm{C}_{\mathrm{j}}$ are calculated in the same manner as for the discharge in long air gaps [33].

The bottom of the negatively charged cloud is considered to behave, in the electrical point of view, as a negative rod electrode having an equivalent radius $r_{p}$ representing an asperity at the bottom of the cloud. The knowledge of the value of this radius enables computing the electric field within the gap as a function of the applied voltage $U_{c}$ and the relative air density $\delta$. In the case of long air gap discharge, the initiation of the first corona occurs when the electric field at the tip of the HV electrode, computed using equation (6), exceeds the threshold field estimated by equation (2). The length of the first corona streamers may be calculated by geometrical method [26]. It supposes that streamers propagation through the gap is achieved by assuming the internal average field that is the stability field $\mathrm{E}_{\mathrm{st}}$, to remain constant. The difference between the initial potential $U_{i}$ and the new potential $\mathrm{U}\left(\mathrm{l}_{\mathrm{s}}\right)$ after the corona initiation is equal to the product $\mathrm{E}_{\mathrm{st}} \mathrm{l}_{\mathrm{s}}$. Its value likely ranges from 50 to $100 \mathrm{~m}$ as observed under the positive polarity $[3,4]$.

If the applied voltage $U_{c}$ and thence the applied geometrical field $E_{A}$ within the gap are sufficient, the criterion of negative leader initiation remains the same as that for the positive 
discharges in long air gaps. At the inception of negative corona, the voltage $\mathrm{U}_{\mathrm{c}}$ is assumed to be constant. The values of $U_{c}$ are generally of some tens of MV for cloud - earth distances varying between $2000 \mathrm{~m}$ and $7500 \mathrm{~m}$ with a mean electric field ranging between $10-15 \mathrm{kV} / \mathrm{m}$ [14].

The initial radius $r_{0}$ of the negative leader is in the range of centimetres [1, 2, 19, 36]. During the development of the lightning discharge, the various parameters of the negative electrode leader versus the discharge current $I_{c}$ are computed at each step of simulation. This concerns the conductivity $\sigma$ and the ionisation degree $\xi$ as well as the reduced electric field $E_{r}=E / N$. E and $\mathrm{N}$ are respectively the internal field and the gas density of the negative electrode leader. These latter vary significantly with scale factor. Due to the lack of available data for negative polarity, these parameters were obtained by extrapolation from the experimental data related to the positive polarity [4].

\section{EQUIVALENT ELECTRICAL CIRCUIT PARAMETERS}

\subsection{THE RESISTANCE}

\subsubsection{THE LEADER CORONA}

The leader corona consists of many filamentary streamer channels. It is assumed to behave as a portion a leader having length $1_{\mathrm{s}}$. Thus the resistance per unit length can be deduced from the following relationship

$\lambda_{s}=\frac{E_{s}}{I_{s}}$

$E_{s}$ is the electric field within the streamer zone; and $I_{s}$ is the current flowing in the streamer zone.

\subsubsection{THE RESISTANCE OF BOTH ELECTRODE AND SPATIAL LEADERS}

Since LTE assumptions do not apply inside leaders, the channels of negative leader are assumed to behave as a resistive electrode; the properties of this later are controlled by Ohmic heating and gas dynamic expansion [31]. In the following, the same relationship of the resistance per unit length will be used for both negative and spatial leaders. Because of the very few information available on the evolution of the lightning discharge channel conductivity, equations derived for long air gap discharge were used. This assumption can be justified by the similarity between both types of discharge. Assuming the leader channel to a cylindrical one, the resistance per unit length can be computed as follow

$\lambda_{1}=\frac{\kappa}{\sigma \pi \mathrm{r}_{1}^{2}\left(\mathrm{t}-\mathrm{t}_{0}\right)}$

where the leader conductivity $\sigma$ is related to the current $I$ [30, 31]. According to Les Renardières Group [31], $\kappa$ is equal to 1 for the positive leader and estimated to 3 for the negative leader. Figure 5 shows the characteristic of the conductivity versus the input current $\sigma=\mathrm{f}(\mathrm{I})$, for $\kappa=1$. Since the actual value of $r_{1}$ depends on the gap length, the conductivity was truncated. For a given gap length and $r_{10}$ as initial radius of the leader channel, the effective conductivity $\sigma$ is truncated

$\sigma_{r}=\left(\frac{r_{l 0}}{r_{l}}\right) \sigma$

The channel cross section at time $t$ and position $z$ is directly related to the charge flow (in non-LTE assumptions [30]) by

$\left(\pi r_{l}^{2}\right)_{z, t}^{2}=\left(\left(\pi r_{l 0}{ }^{2}\right)^{2}+2\left(\frac{\gamma-1}{\gamma}\right) \frac{E_{n, l}}{N} \frac{\pi r_{0}^{2}}{k \tau_{0}} Q(z, t)\right)$

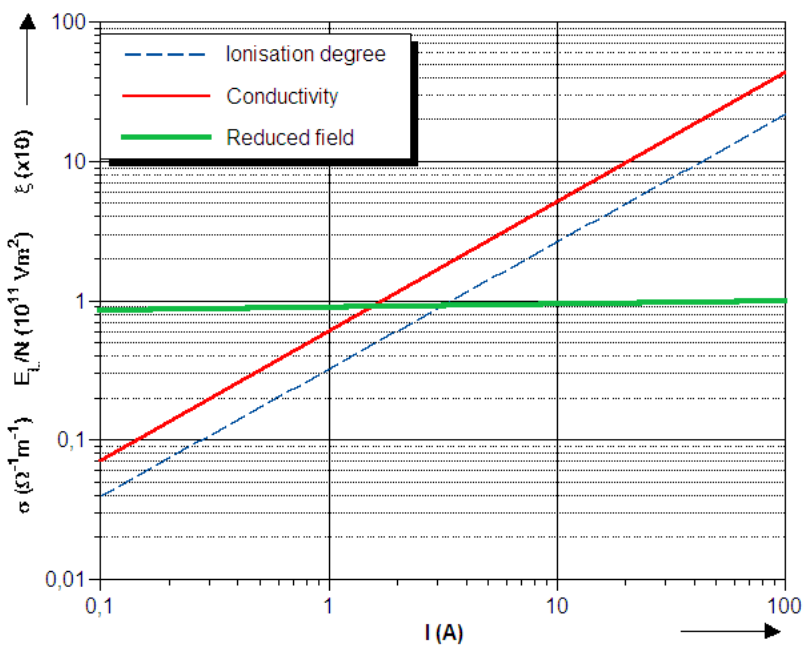

Figure 5. Characteristics of the leader channel as a function of current with $\mathrm{r}_{0}$ $=1 \mathrm{~mm}$ and $\mathrm{T}_{0}=1000^{\circ} \mathrm{K}[31]$.

The initial value of the leader radius $r_{10}$ has been plotted versus the gap length from experimental data [19, 40, 42], as shown in Figure 6.

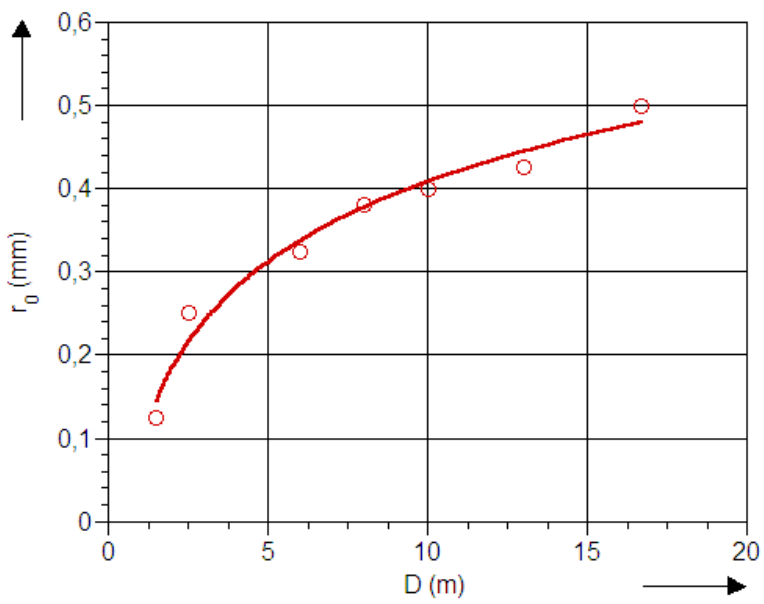

Figure 6. The variation of the leader's initial radius versus the gap length extrapolated from experimental results [30].

Indeed, for a section of the leader channel having a unit length, the power input may be expressed in the form

$E_{n, l} I=\frac{E_{n, l}}{N} I N_{0} \frac{\pi r_{l 0}^{2}}{\pi r_{l}^{2}}$ 
Since $\frac{E_{n, l}}{N}$ is almost constant, the potential gradient $E_{n, l}$ along the leader can be expressed as:

$$
E_{n, l}=\frac{E_{n, l}}{N} \frac{N_{0}}{\left(1+2 \frac{\gamma-1}{\gamma} \frac{E_{n, l}}{N} \frac{Q(t)}{k \tau_{0} \pi r_{l 0}}\right)^{1 / 2}}
$$

where $N\left(\mathrm{~N}=\frac{\sigma}{\mu_{\mathrm{e}} \xi_{e} e}\right)$ is the number of electron in the channel's core of radius $\mathrm{r}$. The quantities $\tau_{0}, \mathrm{~N}_{0}$ and $\mathrm{r}_{10}$ are respectively the gas temperature, the gas number density and the leader tip radius at the time $t_{0}$ at which the leader section is formed; $\mathrm{k}$ is the Boltzmann constant $\left(\mathrm{k}=1.3810^{-23} \mathrm{~J} \mathrm{~K}^{-1}\right)$, $\mu_{\mathrm{e}}$ the electron mobility $\left(\mu_{\mathrm{e}}=0.18 \mathrm{~m}^{2} \mathrm{~V}^{-1} \mathrm{~s}^{-1}\right)$ and $e$ the elementary electron charge $\left(e=1.6 \quad 10^{-19} \mathrm{C}\right)$. The ratio $\gamma$, between the specific heat at constant volume and constant pressure is taken, by hypothesis, constant and equal to 1.4 [30]. The reduced electric field $\frac{E_{n, l}}{N}$, the degree of ionization $\xi$ and the channel conductivity $\sigma$ are related to the current $I$ flowing in the leader channel. Their characteristics have been established by the Les Renardières group [31] (Figure 5). The quantity $\mathrm{Q}(\mathrm{t})$ is defined as

$\mathrm{Q}(\mathrm{t})=\int_{\mathrm{t}_{0}}^{\mathrm{t}} \mathrm{Idt}$

The final jump represents a transition during which the leader conditions may change from non-LTE characteristics to LTE characteristics for the spark channel, a transition which takes place on a much shorter time scale than other discharge phases. The resistance per unit length of the leader decreases sharply. From experimental data [40], a formulation for the resistance $R_{j}$ during this phase was obtained by extrapolation [35].

$$
R_{j}=10^{\left(p^{2}-t / \Delta t\right)^{1 / 2}}
$$

where $\Delta t$ is the duration of the final jump phase and, $\mathrm{p}=$ $\log _{10}\left(R_{\mathrm{fj}}\right), \mathrm{R}_{\mathrm{fj}}$ being the value of the leader resistance $\mathrm{R}_{\mathrm{j}}$ just before the beginning of the final jump.

Concerning the return stroke phase, it is known [40] that the plasma may be assumed to be in LTE within the spark. The gas molecules are fully dissociated and the temperature is uniform throughout the channel. This phase corresponds to the neutralization of charges injected into the gap during the leader propagation. The channel radius is maintained by equal and counteracting magnetic and kinetic forces [43]. The conductivity of a highly ionized gas is given by $\sigma=1.510^{-5} \tau^{\frac{3}{2}}$ $\left(\Omega^{-1} \mathrm{~cm}^{-1}\right)$ [40]. According to Uman [43], the temperature $\tau$ within the channel during the return stroke can exceed 30,000 $\mathrm{K}$. The channel becomes a low impedance path to the ground.

\subsection{THE INDUCTANCE}

The inductance $\mathrm{L}_{\mathrm{lu}}$ per unit length, due to the internal and external flux linkages of the leader channel is determined using the simplification proposed by Fofana and Beroual [32] and Ratnamahilan [44]:

$$
L_{l u}=\frac{\mu_{0}}{2 \pi}\left[0.25+\ln \left(\frac{D_{f}}{r_{l}}\right)\right]
$$

Note that $\mathrm{D}_{\mathrm{f}}$ should be large for transient fields and that the fractional error is of the order of $[1 / \ln (\mathrm{Df} / \mathrm{r})][43] . \mathrm{D}_{\mathrm{f}}$ which represents the distance from the leader channel where the radiated magnetic field is null, should be large enough for transient fields. In fact, simulations show that calculations made with $10 \mathrm{~km}<\mathrm{D}_{\mathrm{f}}<100 \mathrm{~km}$ are correct. Because the fractional error, of the order of $[1 / \ln (\mathrm{Df} / \mathrm{r})]$ should be negligible [43], a value of $100 \mathrm{~km}$ was considered realistic [1].

Equation (31) is also used to compute the inductances per unit length of spatial leader as well as the streamers zone.

During the return stroke phase, the wave is supposed to propagate in TEM mode. Thus, the inductances values may be considered similar to those computed during the discharge development.

\subsection{THE CAPACITANCE 5.3.1 THE LEADER CORONA}

The capacitance $\mathrm{C}_{\mathrm{s}, \mathrm{j}}$ between the discharge channel tip and the head of streamers is computed using a spherical approximation (Figure 7) [35]. Taking into account the fact that the solid angle $\Gamma_{\mathrm{s}, \mathrm{j}}\left(\Gamma_{s, j}=2 \pi\left(1-\cos \theta_{s, j}\right)\right)$ is smaller than $4 \pi$ and knowing that $S>>r_{0}$, it yields

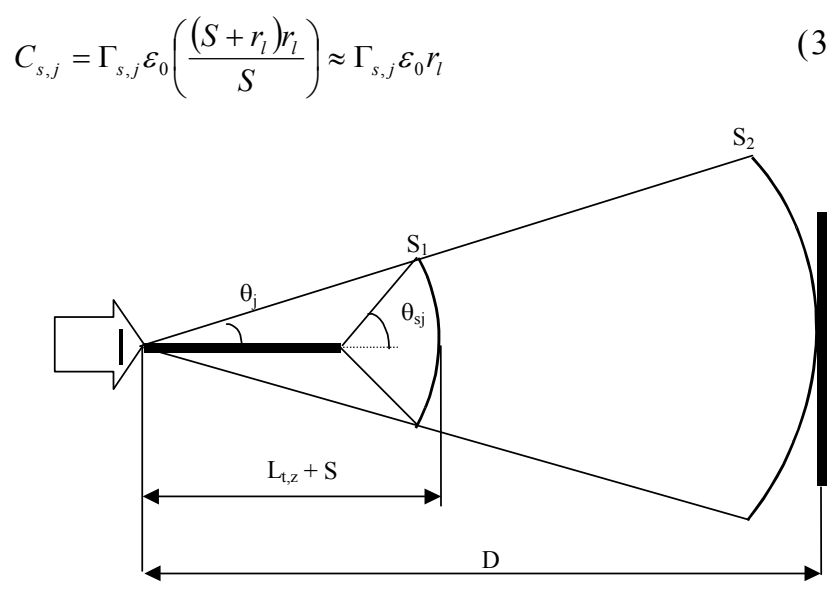

Figure 7. The spherical assumption used in the model.

\subsubsection{THE UNBRIDGED GAP}

The capacitance $C_{j}$ is also determined using the spherical approximation by assuming the leader to a plasma channel surrounded by an envelope of charges induced by the foregoing streamers $[32,38]$. Provided the solid angle $\Gamma$ $(\Gamma=2 \pi(1-\cos \theta))$ is smaller than $4 \pi$, the capacitance is given by the following expression :

$C_{j}=\Gamma_{j} \varepsilon_{0}\left(\frac{D\left(L_{t, z}+S\right)}{Z}\right)$ 
In determining the evolution of $\Gamma_{\mathrm{j}}$, during each leader step, the elementary charge injected can be expressed as

$q_{j, l}=C_{j} U_{j}=\Gamma_{j} \varepsilon_{0}\left(\frac{D\left(L_{t, z}+S\right)}{Z}\right) U_{j}$

The corresponding current flowing inside the channel is $\mathrm{I}=$ $\mathrm{dq}_{\mathrm{j}} / \mathrm{dt}$. Thus, it yields

$I=\frac{d}{d t}\left(\Gamma_{j} \varepsilon_{0}\left(\frac{D\left(L_{t, z}+S\right)}{Z}\right) U_{j}\right)$

which gives

$I=\frac{d \Gamma_{j}}{d t} \varepsilon_{0} \frac{D\left(L_{t, z}+S\right)}{Z} U_{j}+\frac{d U_{j}}{d t} \varepsilon_{0} \frac{D\left(L_{t, z}+S\right)}{Z} \Gamma_{j}+\Gamma_{j} \varepsilon_{0} U_{j} \frac{d}{d t}\left(\frac{D\left(L_{t, z}+S\right)}{Z}\right)$

By setting

$\mathrm{d} \Gamma_{\mathrm{j}}=\Gamma_{\mathrm{j}}-\Gamma_{\mathrm{j}-1}, \frac{d S}{d t}=v_{s}$ and $\frac{d L_{t, z}}{d t} \cos \varphi=v \cos \varphi$,

it yields

$\Gamma_{j}=\frac{\frac{I}{\varepsilon_{0}}+\left(\frac{D\left(L_{t, z}+S\right)}{Z d t}\right) U_{j} \Gamma_{j-1}}{\left(\frac{D\left(L_{t, z}+S\right)}{Z d t}\right) U_{j}+\frac{d U_{j}}{d t}\left(\frac{D\left(L_{t, z}+S\right)}{Z}\right)+U_{j}\left(\frac{(M-N)}{Z^{2}}\right)}$

where

$M=\left(D^{2}-D\left(L_{t, z}+S\right)\right)\left(v \cos \varphi+v_{s}\right)$

$N=-\left(v_{S}+v_{n, l} \cos \varphi\right) D\left(L_{t, z}+S\right)$

Computations revealed that $\mathrm{R}_{\mathrm{s}, \mathrm{j}} \mathrm{C}_{\mathrm{s}, \mathrm{j}}$ is very low with respect to $\mathrm{R}_{\mathrm{j}} \mathrm{C}_{\mathrm{j}}$ and consequently $\mathrm{C}_{\mathrm{s}, \mathrm{j}}$ can be neglected. Equation (38) allows calculation of $\Gamma_{\mathrm{j}}$, which depends on $\Gamma_{\mathrm{j}-1}$. To start the simulation a conical angle of the first corona $\theta_{0}=\pi / 6$, is considered. Indeed, using image converters in framing mode, the leader corona is observed to be a conical luminous region of angle about $70^{\circ}[14]$ whose apex is near the leader tip.

\section{CONCLUSIONS}

The self-consistent mathematical model presented here enables predicting the entire negative lightning discharge. It emphasizes the step-like characteristic of such a discharge and provides the spatial and temporal evolution of the different characteristics of the discharge such as trajectory, current and the corresponding electrical charge, energy and power injected into the gap, potential gradient in the leader channel, voltage at the tip of the discharge, temporal evolution of the channel thermal radius, and the instantaneous propagation velocity.

\section{REFERENCES}

[1] M. A. Uman, The Lightning Discharge, International Geophysics Series, Edited by William L. Donn, Vol. 39, Academic Press, San Diego, California, (USA), 1987.

[2] E. M. Bazelyan and Y. P. Raizer, "Lightning Physics and Lightning Protection", Institute of Physics Publishing (IOP), Bristol UK, and Philadelphia, USA, 2000.
[3] I. Fofana and A. Beroual, "Modeling of the leader and the return stroke currents with an equivalent electrical network", $9^{\text {th }}$ Int. Symp on High Voltage Engineering, Graz, Austra, paper 2141, 1995.

[4] I. Fofana and A. Beroual, "A positive Lightning stepped leader model based on the similarity with long laboratory spark", $23^{\text {rd }}$ Intern. Conf. Lightning Protection, Firenze, Italy, pp. 393-398, 1996.

[5] P. Johannet, "Modélisation opérationnelle du canal de foudre", bulletin de la Direction des Études et Recherches d'Électricité De France, série B, No.2, pp. 59-72, 1987.

[6] P. Lalande A. Bondiou-Clergerie, P. Laroche, G. L. Bacchiega, A. Bonamy, I. Gallimberti, A. Heybert-Berard, J. P. Berlandis and B. Bador, "Modeling of the lightning connection process to a ground structure", $23^{\text {rd }}$ International Conference on Lightning Protection, Firenze, Italy, pp. 429-33, 1996.

[7] P. Lalande, "Etude des conditions de foudroiement d'une structure au sol", Thèse de doctorat, Université de Paris 11, Orsay, France, 1996.

[8] C. N. Richards and G. A. Dawson, "The hydrodynamic instability of water drops falling at terminal velocity in vertical electric fields", J. Geophys. Res., Vol. 76, pp. 3445-3455, 1971.

[9] B. F. Schonland, "Progressive lightning - Part IV: the discharge mechanism". Proc. Roy. Soc., Serie A, Vol. 164, pp. 132-150, 1938.

[10] H. Kasemir, "Static discharge and triggered lightning", Proceeding $8^{\text {th }}$ Int. hältnisse bei einer Blitzentladung in der Gewitterwolke, dar gewitter, H. Israel Akad. Verlag, Leipzig (Germany), 1983.

[11] P. Richard, A. Delannoy, G. Labaune, P. Laroche, "Results of spatial temporal characterization of the VHF-UHF radiation of lightning", J. Geophys. Res., Vol. 91, No. 1, pp. 1248-1260, 1986.

[12] V. Mazur, "A physical model of lightning initiation on aircraft in thunderstorms", J. Geophys. Res. Vol. 94, No. 3, pp. 3326-3340, 1989; and V. Mazur, E. Williams, R. Boldi, L. Maier and D. E. Proctor, "Initial comparison of lightning mapping with operational Time-OfArrival and Interferometric systems", J. Geophys. Res., 102(D10), pp. 11,071-11,085, 1997.

[13] A. Bondiou, I. Taudière, P. Richard, F. Helloco, "Analyse spatiotemporelle du rayonnement VHF-UHF associé à l'éclair", Revue Phys. Appl., Vol. 25, pp. 147-157, 1990.

[14] M. Aguet and M. Ianoz, "Haute Tension", Traité d'électricité, d'électronique et d'électrotechnique, Vol. XXII, Presses Polytechniques et Universitaires Romandes, Paris, Dunod, 1987.

[15] C. Gary, A. Cimador, R. Fieux, "La foudre: étude du phénomène application à la protection des lignes de transport", Revue Générale d'Électricité (RGE), Vol. 84, No.1, pp. 24-35, 1975.

[16] M. Rubinstein, F. Rachidi, M. A. Uman, R. Thottapillil, V. A. Rakov and A. Nucci, "Characterization of vertical electric fields $500 \mathrm{~m}$ and 30 $\mathrm{m}$ from triggered lightning", J. Geophys. Res., 100, No D5, pp. 8863$8872,1995$.

[17] H. D. Betz, U. Schumann and P. Laroche, "Lightning: Principles, Instruments and Applications - Review of Modern Lightning Research", Springer ISBN 978-1-4020-9078-3, 641 pages, December 2008.

[18] H. Raether, Electron Avalanches and Breakdown in Gases, Butterworths, London, 1964.

[19] P. Ortéga, "Comportement diélectrique des grands intervalles d'air soumis à des ondes de tension de polarité positive ou négative", Thèse de doctorat, Université de Pau, 1992.

[20] B. Hutzler and D. Hutzler, "A model of breakdown in large air gaps", Bulletin de la Direction des Études et Recherches d'Électricité De France, No. 4, pp. 11-39, 1992.

[21] C. Gary, G. Le Roy, B. Hutzler, J. Lalot and C. Dubanton, "Les propriétés diélectriques de l'air et les très hautes tensions", Collection de la Direction des Études et Recherches d'Électricité De France, No.51, Eyrolles, 1984.

[22] N. T. Giao, "Partial discharge in air, part II: selection of line conductors", IEEE Electr. Insulation Magazine, Vol. 2, No.3, pp. 5-11, 1995.

[23] F. D'Alessandro and J. R. Gumley, "A Collection Volume Method for the placement of air terminals for the protection of structures against lightning", J. Electrostatics Vol. 50, pp. 279-302, 2001.

[24] I. Fofana and A. Béroual, "A quantitative study of lightning striking distance factors", Proc. of the $27^{\text {th }}$ Intern. Conf. Lightning Protection, Avignon, France, pp. 421-426, 2004.

[25] N. Goelian, P. Lalande, A. Bondiou-Clergerie, G. L. Bacchiega, A. Gazzani, I. Gallimberti, "A simplified model for the simulation of positive-spark developpment in long air gaps", J. Phys.D: Appl. Phys, Vol. 30, pp.2441-2452, 1997. 
[26] A. Bondiou and I. Gallimberti, "Theoretical modelling of the development of positive spark in long gaps", J. Phys. D: Appl. Phys., Vol. 27, pp. 1252-1266, 1994.

[27] A. Beroual, "Modélisation de la longue décharge négative par des circuits - Application à la foudre", Revue d'Électricité et d'Électronique, No. 8, pp. 36-43, 2004.

[28] A. Beroual, "Electronic gaseous processes in the breakdown phenomena of dielectric liquids", J. Appl. Phys., Vol. 73, pp. 4528-4533, 1993.

[29] A. Beroual, "Universal dynamic model of discharge propagating in air, liquids, solid/liquid interfaces and polluted", $13^{\text {th }}$ Intern. Sympos. High Voltage Eng. (ISH), Delft, The Nedherlands, 2003.

[30] Les Renardières Group, "Double-impulse tests of long air gaps", Proc. IEE, Vol. A 133, pp. 395-483, 1986.

[31] Les Renardières Group, "Positive discharges in long air gaps at les Renardières", Electra 53, pp. 31-153, 1977.

[32] I. Fofana and A. Beroual, "A new proposal for calculation of the leader velocity based on energy considerations", J. Phys. D: Appl. Phys., Vol. 29, pp. 691-696, 1996.

[33] J-H. Rakotonandrasana, A. Beroual and I. Fofana, "Modelling of the negative discharge in long air gaps under impulse voltage", J. Phys. D: App. Phys., Vol. 41, 105210 (15pp), 2008.

[34] E. M. Bazelyan, Y. P. Raizer and N. L. Aleksandrov, "The effect of reduced air density on streamer-to-leader transition and on properties of long positive leader”, J. Phys. D: Appl. Phys., Vol. 40, 4133-4144, 2007.

[35] I. Fofana and A. Beroual, "A Predictive Model of Positive Discharge in Long Air Gaps under Pure and Oscillating impulse Shapes", J. Phys. D: Appl. Phys., Vol. 30, pp. 1653-67, 1997.

[36] Groupe des Renardières, "L'amorçage en polarité négative des grands intervalles d'air aux Renardières", Electra, No.74, 1981.

[37] G. L. Bacchiega, A. Gazzani, M. Bernardi, I. Gallimberti, A. BondiouClergerie, "Theoretical modelling of the laboratory negative stepped leader", $16^{\text {th }}$ International Aerospace and Ground Conf. on Lightning and Static Electricity (ICOLSE), Mannheim - Germany, pp. 13-22, May 24-27, 1996.

[38] I. Fofana and A. Beroual, "Modelling of the leader current with an equivalent electrical network", J. Physics D: Appl. Phys., Vol. 28, pp. 305-313, 1995.

[39] H. Garcia and B. Hutzler, "Electrical breakdown in long air gaps. The final jump", IEE Conf. on Gas Discharges, London, pp. 206-210, 1974.

[40] I. Gallimberti, "The mechanism of long spark formation", J. Physique, C7, Vol. 40, , No.7, pp. 193-205, 1979.

[41] I. Fofana, A. Ben Rhouma, A. Beroual, P. Auriol, "Modeling Positive Lightning Stepped Leader and Studying its Effects on Engineering Systems" IEE Proc. - Generation, Transmission and Distribution, Vol. 145, No.4, pp. 395-402, 1998.

[42] P. Domens, "Contribution à l'étude des décharges électriques dans les grands intervalles d'air", Thèse de Doctorat d'Etat ès sciences, Université de Pau, France, 1987.

[43] M. A. Uman, "Determination of lightning temperature", J. Geophys. Res., Vol. 56, pp. 949-957, 1969.

[44] P. Ratnamahilan, "Modeling the lightning earth flash return stroke for studying its effects on engineering systems", IEEE Trans. Magnetics, Vol. 29, pp. 1839-1844, 1993.

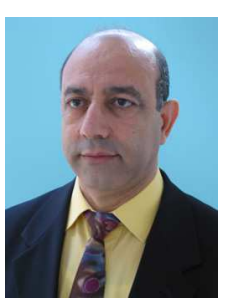

Abderrahmane Beroual (M'92, SM'09) is currently Professor at the Ecole Centrale de Lyon, France. Presently, he is the head of the Dielectric Materials and High Voltage Group at AMPERE Lab - CNRS as well as Responsible of the Master Research Program in electrical engineering. From 1994 to 1998, he chaired the International Study Group on Streamer Propagation in Liquids of the IEEE - DEIS. He is member of many Advisory Committees of International Conferences (ICDL, ISH, APTADM, Gas Discharge, ICHVE, CMD, INSUCON, NIWE, iREED, Technical Committee of the IEEE CEIDP, UF10 Technical Commission - MT30 of IEC) and responsible of various research projects. His main research interests include high voltage insulation, dielectric materials, long air gaps discharge and lightning, modeling of discharges and composite materials. He supervised more than $40 \mathrm{PhD}$. Students. He is author/co-author of more than 300 technical papers including more than 110 refereed journal papers, 4 patents and 5 book chapters.

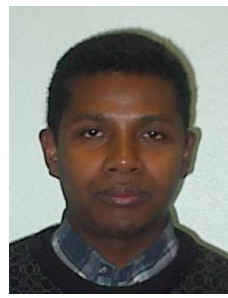

Jean Hubert Rakotonandrasana received the Dipl. Ing. and Ph.D. degrees in electrical engineering, respectively in 2000 from the Ecole Polytechnique Fédérale of Lausanne, Switzerland and in 2008 from the Ecole Centrale de Lyon (ECL), France. He is presently an assistant professor at the EIA at Lausanne and associate researcher at AMPERE lab. - ECL where he is a member of the Dielectric Materials and High Voltage Research Group. His main research interest is the modeling of long discharge. He authored/coauthored 10 technical papers.

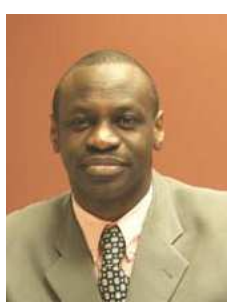

Issouf Fofana (M'05-SM'09) is currently Professor at the Université du Québec à Chicoutimi (UQAC), Quebec, Canada. Since September 2005, Dr Fofana is Chair holder of the Canada Research Chair, tier 2, on Insulating Liquids and mixed dielectrics for Electrotechnology (ISOLIME). He is registered as a professional engineer in the province of Quebec, and is currently appointed to the Technical Committee of the IEEE CEIDP and the International Advisory Committee of the IEEE ICDL. He is a member of the IEEE Task Force on Atmospheric Icing performance of line insulators and member of the ASTM D27 Task Group to develop a test method for Partial Discharge Inception Voltage. He has authored/co-authored over 140 scientific publications including 3 patents and 2 book chapters. 